\title{
NEW HOPE FOR DEALING WITH "SUPERBUGS"
}

\author{
D. Simren ${ }^{1}$, R. Yordanova ${ }^{2 *}$ \\ ${ }^{1}$ Faculty of Medicine, Trakia University, Stara Zagora, Bulgaria \\ ${ }^{2}$ Medical College, Trakia University, Stara Zagora, Bulgaria
}

\begin{abstract}
Introduction: Antimicrobial resistance has become one of the biggest threats to global health. Because of the variety of resistance mechanisms that "superbugs" acquire under the wide antibiotic pressure in medicine, they become difficult to treat with commonly used antibiotics. The spread of so-called "therapeutic problematic microorganisms" results in extremely limited treatment options of infections, prolonged hospital stay, increased treatment costs and in many cases, the inability to adequately treat and increased mortality. The new strain of bacteria Streptomyces sp. myrophorea was found to be effective at killing both Gram-positive and Gram-negative multidrug resistant pathogens on the World Health Organization's priority list. The purpose of this review is to provide information about Streptomyces sp. myrophorea. Materials and methods: a review of scientific literature, studies, and international experience that provide information on Streptomyces sp. myrophorea. Conclusion: The "superbug" problem may be alarming, with news that even our last resort antibiotics are beginning to fail, but there is hope - Streptomyces sp. myrophorea.
\end{abstract}

Key words: Streptomyces sp. myrophorea, antimicrobial resistance, therapeutic problematic microorganisms.

\section{INTRODUCTION}

Increasing antimicrobial resistance has become a significant public health concern as there are a limited number or even sometimes no effective agents for infections caused by these bacteria. According to recent research, antibiotics resistant "superbugs" could kill up to 1.3 million people in Europe by 2050 (1). Because of the variety of resistance mechanisms that these microorganisms acquire under the wide antibiotic pressure in medicine, they become difficult to treat with commonly used antibiotics. The spread of so-called "therapeutic problematic microorganisms" results in extremely limited treatment options of infections, prolonged hospital stay, increased treatment costs and in many cases, the inability to adequately treat and increased mortality. Multidrug resistant organisms

\footnotetext{
*Correspondence to: Yordanova Rozalina, Medical College, Trakia University, Stara Zagora, Bulgaria, 6000 Stara Zagora, Bulgaria, mobile: +359883335099,e-mail: rozalina_@abv.bg
}

(MDROs) usually require treatment with higher levels of antibiotics or antibiotics of last resort, but there is no guarantee of success and treatment may include expensive and sometimes toxic chemotherapy (2). The World Health Organization (WHO) has therefore created an urgent priority list for the discovery of new antibiotics (3).

Part of the bacteria exhibiting multidrug resistance (MDR) is the members of so-called ESKAPE group (Enterococcus faecium, Staphylococcus aureus, Klebsiella pneumoniae, Acinetobacter baumannii, Pseudomonas and Enterobacter species). $\quad$ ESKAPE pathogens are associated with the highest risk of mortality thereby resulting in increased health care costs (4). They are responsible for the most hospital-acquired infections (HAIs) and have created an urgent need for research and development of novel therapeutics $(3,5)$. 
Current strategies to find replacement therapy and combat multidrug resistance encourage researchers to explore new sources, including niche environments such as thermal vents, deserts, and alkaline environments, in the hope that they can produce varieties of current antibiotics $(6,7)$. In fact, the alkaline environment has been proven a rich source of antibiotics, many of which derived from Streptomyces bacteria $(6,8)$. Actinomycetes, members of the Actinobacteria phylum are responsible for the synthesis of more than half of modern drugs, including antimicrobial, anticancer, antiviral, antifungal, and antiparasitic compounds (9-12).

Even though ancient medical traditions are less known in Europe (13), the traditional medicines research or so-called ethnopharmacology turns out to be another promising way to (re)discover drugs (14). In Boho region, Northern Ireland the soil has alkaline and high radon character and was deposited in the late Pleistocene period (about $9,126,000-11,700$ years ago) at the base of the Carboniferous Dartry limestone (approximately 335 million years) (15). It is in this alkaline soil that the last remnants of continuous ethnopharmacological culture cure can be found (16).

Traditionally, a small amount of soil was used to treat a variety of conditions from toothache to infections (14). There is no documentation regarding the exact origin of the cure, but there are still some written documents related to the area inhabited by Neolithic people approximately 4000 years ago and by the Druids 1500 years ago and where the grave of the priest and healer James McGirr (died in 1815 ) is located (17).

On $28^{\text {th }}$ July 2015 , according to the traditional practices, a research team from the United Kingdom and Croatia, collected and dispatched for laboratory analysis soil samples from an alkaline escarpment region from Sacred Heart Church, Boho, Fermanagh, United Kingdom (18). Aliquots of diluted soil samples were cultivated on International Streptomyces Project 2 (ISP) agar and Starch agar for initial isolation of Streptomyces and Soy Flour Mannitol (SFM) was used for Streptomyces subculture and growth (14).

In preliminary screening of soil sample were isolated eight Streptomyces-like colonies with different morphology and growth characteristics. The Streptomyces isolate showed the most constant inhibitory activity against Gram-positive was original called Streptomyces sp. myrophorea, McG1 isolate and was further characterized and tested (14). Although the $\mathrm{pH}$ of the Boho soil sample was around 8 , the isolate demonstrated ability to grow at pH 10.5 (14) which suggested not only tolerance of high alkaline conditions therefore capacity to grow in an extreme environment.

Streptomyces sp. myrophorea characteristics: Streptomyces sp. myrophorea, McG1 isolate forms powdery light to dark green colonies on SFM agar that emitted a clearly "germaline" odor after 3-5 days period. It is a spore forming bacteria with very slender vegetative and aerial hyphae and green or very light green/white spores when cultured. Atomic Force Microscopy conducted in air, using TESPA cantilevers in Tapping Mod was used to visualize Streptomyces hyphae growing and spore forming on glass cover slips (14).

Antimicrobial potential of Streptomyces sp. myrophorea McG1 isolate: To test the antimicrobial potential of Streptomyces sp. myrophorea, McG1 isolate were used multidrug resistant ESKAPE pathogens isolated from different Croatian hospitals. Initially, cores from the Streptomyces were incorporated in Mueller-Hinton agar and afterwards overlaid with a suspension of ESKAPE pathogens (14). The controls consist of ampicillin $20 \mu \mathrm{g}$, chloramphenicol $20 \mu \mathrm{g}$, ciprofloxacin $5 \mu \mathrm{g}$, gentamicin $30 \mu \mathrm{g}$, kanamycin $10 \mu \mathrm{g}$, streptogramin $10 \mu \mathrm{g}$, and ampicillin $10 \mu \mathrm{g}+$ sulbactam $10 \mu \mathrm{g}(14)$.

\section{RESULTS}

The incubation of multidrug resistant both Gram-positive and Gram-negative bacteria ESKAPE pathogens reveal that Streptomyces $s p$. myrophorea, isolate McG1 has the capacity to inhibit the growth of many of themvancomycin-resistant $E$. faecium, methicillinresistant $S$. aureus, carbapenem-resistant $A$. baumannii and K. pneumoniae. Some of these bacteria urgently require the development of new antibiotics and some of them have been reported from WHO in high priority pathogens list. It was found that Streptomyces $s p$. myrophorea has limited effects against strains of E. faecium and P. aeruginosa (14). The genome sequence of Streptomyces sp. myrophorea, McG1 isolate was deposited at the NCBI (TaxID 2099643) (14). 


\section{CONCLUSION}

The global increase in multidrug resistant ESKAPE pathogens as created an urgent need to develop replacement therapies. Infections with MDROs are extremely hard to treat and may spread throughout a hospital or community environment. The "superbug" problem may be alarming, with news that even our last resort antibiotics are beginning to fail, but there is hope. The new strain of bacteria Streptomyces sp. myrophorea, McG1 isolate discovered by a team based in Swansea University Medical School was found to be effective at killing several multidrug resistant pathogens. It inhibits the growth of four of the top six, both Gram-positive and Gram-negative multidrug resistant bacteria on the World Health Organization's priority list.

\section{REFERENCES}

1. Swansea University. (2018, December 27). Bacteria found in ancient Irish soil halts growth of superbugs: New hope for tackling antibiotic resistance. ScienceDaily. Retrieved June 13, 2020 from www.sciencedaily.com/releases/2018/12/18 1227111427.htm.

2. Santajit, S., and Indrawattana, N. Mechanisms of antimicrobial resistance in ESKAPE pathogens. Biomed Res. Int. 2016:2475067, 2016.

3. Tacconelli, E., Carrara, E., Savoldi, A., Harbarth, S., Mendelson, M., Monnet, D. L., et al. Discovery, research, and development of new antibiotics: the WHO priority list of antibiotic-resistant bacteria and tuberculosis. Lancet Infect. Dis. 18, 318-327, 2018.

4. Founou R. C., Founou L. L., Essack S. Y. Clinical and economic impact of antibiotic resistance in developing countries: a systematic review and meta-analysis. PLoS ONE 12:e0189621. 10.1371/journal.pone.0189621, 2017.

5. Jelic, M., Skrlin, J., Bejuk, D., Koscak, I., Batik, I., Guzvinec, M., et al. Characterization of isolates associated with emergence of OXA-48-producing Klebsiella pneumoniae in croatia. Microb. Drug Resist. 24, 973-979, 2017.

6. Sato, M., Beppu, T., and Arima, K. Studies on antibiotics produced at high alkaline $\mathrm{pH}$. Agric. Biol. Chem. 47, 2019-2027, 1983.

7. Mohammadipanah, F., and Wink, J. Actinobacteria from arid and desert habitats: diversity and biological activity. Front. Microbiol. 6:1541, 2015.
8. Maciejewska, M., Adam, D., Martinet, L., Naome, A., Calusinska, M., Delfosse, P., et al. A phenotypic and genotypic analysis of the antimicrobial potential of cultivable Streptomyces isolated from cave moonmilk deposits. Front. Microbiol. 7:1455, 2016.

9. Noomnual, S., Thasana, N., Sungkeeree, P., Mongkolsuk, S., and Loprasert, S. Streptanoate, a new anticancer butanoate from Streptomyces sp. DC3. J. Antibiot. 69, 124-127, 2016.

10. Yokomizo, K., Miyamoto, Y., Nagao, K., Kumagae, E., Habib, E. S., Suzuki, K., et al. Fattiviracin A1, a novel antiviral agent produced by Streptomyces microflavus strain No. 2445. II. Biological properties. $J$. Antibiot. 51, 1035-1039, 1998.

11.Nguyen, T. M., and Kim, J. Antifungal and antibacterial activities of Streptomyces polymachus sp. nov. Isolated from soil. Int. J. Syst.Evol. Microbiol. 65, 2385-2390, 2015.

12.Procopio, R. E., Silva, I. R., Martins, M. K., Azevedo, J. L., and Araújo, J. M. Antibiotics produced by Streptomyces. Braz. J. Infect. Dis. 16, 466-471, 2012.

13.Behroozian, S., Svensson, S. L., and Davies, J. Kisameet clay exhibits potent antibacterial activity against the eskape pathogens.mBio7, e1842-e1815, 2016.

14. Terra L, Dyson PJ, Hitchings MD, Thomas L, Abdelhameed A, Banat IM, Gazze SA, Vujaklija D, Facey PD, Francis LW and Quinn GA. A Novel Alkaliphilic Streptomyces Inhibits ESKAPE Pathogens. Front. Microbiol. 9:2458, 2018.

15.Brunton, C. H. C., and Mason, T. R. Palaeoenvironments and correlation of the carboniferous rocks in West Fermanagh. Northern Ireland. Bull. Br. Mus. Nat. Hist. Geol. 32, 91-108, 1979.

16.Foley, R. Indigenous narratives of health: $(\mathrm{Re})$ placing folk-medicine within irish health histories. J. Med. Humanit. 36, 5-18, 2015.

17. Gallachair, P. Ó. Clogherici: a dictionary of the catholic clergy of the diocese of clogher (1535-1835) (continued). Clogher Rec. 8, 271-280, 1975.

18.Donnelly, C., Mac Donald, P., Murphy, E., and Beer, N. Excavations at boho high cross, toneel north, county fermanagh. Ulst. J. Archaeol.62,121-142, 2003. 